\title{
CHALLENGES IN ACHIEVING THE SUSTAINABLE DEVELOPMENT GOAL ON GOOD HEALTH AND WELL-BEING: GLOBAL GOVERNANCE AS AN ISSUE FOR THE MEANS OF IMPLEMENTATION
}

\author{
Yasushi Katsuma, Hideaki Shiroyama and Makiko Matsuo*
}

To formulate health development policy and strategies aimed at the Sustainable Development Goal 3, which seeks to ensuring health and well-being for all, it is indispensable to revisit the issue of global health governance in the wake of the Ebola virus disease outbreak in West Africa. The issue of global health governance is also relevant in the AsiaPacific region, where Severe Acute Respiratory Syndrome (SARS), influenza $A$ (H1N1) and the Middle East respiratory syndrome coronavirus (MERS-CoV) were health security threats. The failure to respond timely and effectively to the health crisis was derived from a few factors that are relevant to the means of implementation necessary to achieve the Sustainable Development Goals. During ordinary times, efforts to enhance health systems should include building the core capacities of the International Health Regulations (IHR), which should be supported not only by the World Health Organization (WHO), but also through coordination among diverse multilateral and bilateral organizations as part of their health development cooperation programmes associated with achieving the Sustainable Development Goals. To enhance preparedness for handling health crises, the organizational capacities of

\footnotetext{
* Yasushi Katsuma, Professor (e-mail: katsuma@waseda.jp) is from the Graduate School of Asia-Pacific Studies, Waseda University, and from the Institute for Global Health Policy of the National Center for Global Health and Medicine, Japan. Hideaki Shiroyama, Professor, and Makiko Matsuo, Project Assistant Professor, are from the University of Tokyo. The authors are deeply indebted to the Japan Center for International Exchange (JCIE) for assisting this research and arranging interviews in Geneva, New York, Tokyo and Washington, D.C. The lead author presented some of the basic ideas of this paper for comments at the North-East Asia Development Cooperation Forum 2015 organized by the Economic and Social Commission for Asia and Pacific (ESCAP) and the Japan International Cooperation Agency (JICA) on 31 October 2015. A draft version of this paper prepared by the three authors was presented for comments at a round table entitled "Promoting universal health coverage to achieve human security: proposals for the G7 Ise-Shima Summit in Japan" organized by the Global Health Working Group for the 2016 G7 Summit in Tokyo on 17 December 2015. The lead author appreciates the support extended by the Japan Society for International Development (JASID) in improving the quality of this paper.
} 
WHO and its regional offices need to be strengthened. In addition, coordination among WHO and other actors should be facilitated in accordance with the situational categories based on the combination of (a) the capacity of the country where an outbreak of an infectious disease is occurring and (b) the severity and magnitude of that infectious disease.

JEL classification: I14, I18, K32.

Keywords: Ebola, global health governance, infectious diseases, International Health Regulations (IHR), public health emergency of international concern, public health emergency of international concern (PHEIC), Sustainable Development Goals.

\section{BACKGROUND}

The Millennium Development Goals have been replaced by the Sustainable Development Goals, as a result of the adoption of the 2030 Agenda for Sustainable Development by the General Assembly in September 2015. The United Nations Member States, including both developing and developed countries, and their civil society organizations are determined to achieve the Sustainable Development Goals by 2030 . To formulate a development policy and strategies, the importance of the means of implementation has been stressed. However, discussions on the means of implementation often focus only on financial resources, and fail to give enough attention to the issue of global governance for development.

The issue of global governance is particularly important for health. To achieve the Sustainable Development Goal 3 and its related targets, to ensure healthy lives and promote well-being for all at all ages by 2030, it is important to formulate a health development policy and strategies to end the epidemics of AIDS, tuberculosis, malaria and neglected tropical diseases, as well as to combat hepatitis, water-borne diseases and other communicable diseases (target 3.3). In addition, another target is to achieve universal health coverage, including financial risk protection, access to quality essential health care services, and access to safe, effective, quality and affordable essential medicines and vaccines for all (target 3.8). The Sustainable Development Goal 3 is also aimed at strengthening the capacity of all countries, particularly developing countries, for early warning, risk reduction, and management of national and global health risks (target 3.d). However, in the efforts to achieve this Goal and its related targets, there are a number of challenges associated with the means of implementations, as the existing institutional arrangements may be inadequate in providing an enabling environment for diverse organizations to cooperate each other. 
When discussing the means of implementation in achieving the Sustainable Development Goal 3, it is indispensable to revisit the issue of global health governance by reviewing the outbreak of Ebola virus disease in West Africa in 2014 and the failure to respond timely and effectively to the health crisis. The issue of global health governance is also relevant in the Asia-Pacific region where the severe acute respiratory syndrome (SARS) in 2003, the pandemic influenza A (H1N1) in 2009-2010, and the Middle East respiratory syndrome coronavirus (MERS-CoV) in 2015 were health security threats.

The number of deaths from the Ebola virus disease, which spread mainly throughout three countries in West Africa (Guinea, Liberia and Sierra Leone), reached 11,323 , and the number of those infected with the virus (including suspected cases) totalled 28,646, as of 27 March 2016 (WHO, 2016). Since the Ebola virus disease was discovered in 1976, the 2014 outbreak has proven to be the most serious and complex.

At the initial stage, the Médecins Sans Frontières (MSF) issued warnings repeatedly, stating that the "geographical expansion (of Ebola) was unprecedented" in March 2014, and "uncontrollable" in June 2014 (MSF, 2015, pp. 6-7). However, those warnings failed to cause a stir at the sixty-seventh World Health Assembly of the World Health Organization (WHO) held that same year, and an international response was not launched immediately. It was only after August that the outbreak was recognized as a "public health emergency of international concern (PHEIC)" in accordance with International Health Regulations (IHR). ${ }^{1}$ However, by the time PHEIC was declared, it was already impossible for WHO alone to coordinate countries' efforts to contain the epidemic.

Faced with such a situation, Secretary-General Ban Ki-moon and the then Chef de Cabinet Susana Malcorra initiated an unprecedented response. In September 2014, the United Nations Mission for Ebola Emergency Response (UNMEER) was created with the endorsement of the General Assembly in its resolution 69/1 and the Security Council in its resolution 2177. It was the first United Nations mission ever to respond to a global health threat. Based on the UNMEER appeal, United Nations agencies, concerned international organizations, non-governmental organizations (NGOs), and other partners came together to meet in Accra in October to decide on their division of work within a common framework. Under this process, a coordination mechanism for a global emergency response was put in place, with UNMEER at the core. Previous individually deployed responses were finally consolidated, and the

Under IHR, PHEIC is defined as an extraordinary event which is determined to (a) constitute a public health risk to other States through the international spread of disease and to (b) potentially require a coordinated international response. 
necessary resources were secured and reallocated. Subsequently, the number of people infected decreased dramatically in those three West African countries.

The United Nations Mission for Ebola Emergency Response was closed at the end of July 2015, as its mission had ended. Authority for overall management was subsequently handed over to WHO. Currently, the international community's interest has moved on to reviewing the lessons learned from the unprecedented emergency response. With regard to this, the questions are how to respond to future health emergency situations and how to enhance preparedness by strengthening sustainable health systems, as part of the efforts to achieve the Sustainable Development Goals.

\section{DEBATE ON GLOBAL HEALTH GOVERNANCE}

A variety of actors are currently discussing the response to Ebola, and reviewing the global health governance precipitated by the outbreak (Briand and others, 2014; Gostin, 2014; Gostin and Friedman, 2014; Kruk and others, 2015).

The World Health Organization also set up the Ebola Interim Assessment Panel, which released a report in July 2015 with recommendations. Based on these proposals, various reforms have already being initiated (WHO, 2015b). Concerning internal reforms of $\mathrm{WHO}$, first, the organization presented "a roadmap for action" in September 2015 (WHO, 2015a). Second, the emergency response was discussed by the Advisory Group on Reform of WHO's Work in Outbreak and Emergencies, chaired by Dr. David Nabarro, who is the Secretary-General's Special Envoy on Ebola, under the leadership of the WHO secretariat Director-General Dr. Margaret Chan (WHO Advisory Group, 2015). The Advisory Group released its second report in January 2016 in which the organizational structure of the new Programme for Outbreaks and Emergencies was proposed. Third, the effectiveness of IHR in facilitating the response to Ebola was assessed and debated by the Review Committee on the Role of the 2005 IHR in the Ebola Outbreak and Response. Its report (A69/21) was submitted to the sixty-ninth World Health Assembly, which was held in 2016. In response, the Director-General presented a report "Reform of WHO's work in health emergency management: WHO Health Emergencies Programme."

Additionally, the Secretary-General has established a High-level Panel on the Global Response to Health Crises for the purpose of conducting a review that is not limited to the Ebola outbreak, but also to consider global and national health governance more comprehensively. The High-level Panel submitted a report "Protecting humanity from future health crises" (A/70/723) to the Secretary-General. In this context, the WHO Director-General released a report "Strengthening the global 
health architecture: implementation of the recommendations of the High-level Panel on the Global Response to Health Crises, Report of the Secretary-General."

A number of research institutions, universities, and international NGOs have also conducted reviews from their own perspectives. These include, among others, (a) a review The Neglected Dimension of Global Security: A Framework to Counter Infectious Disease Crises by the National Academy of Medicine (NAM), ${ }^{2}$ (b) a joint initiative by Harvard University and the London School of Hygiene and Tropical Medicine (Moon and others, 2015), (c) a review by an independent panel set up by the Bill and Melinda Gates Foundation and (d) a review by MSF (2015).

\section{ANALYSIS OF THE RESPONSE TO THE EBOLA OUTBREAK}

\section{Purpose of the study}

The purpose of the present study is to (a) analyse the process and issues of the response to Ebola at the national and international levels, (b) set forth lessons to be learned, and then present options for responding to potential outbreaks, presenting implications about the way in which global health governance should be arranged, and (c) discuss how the means of implementation necessary to achieve the Sustainable Development Goals should be addressed.

\section{Research methodology}

The research methods employed are principally studies of documents, such as primary documents, secondary documents and academic papers and interviews conducted in Geneva, New York, Tokyo and Washington, D.C. Regarding research carried out in Switzerland and the United States of America, interviews were conducted in July and November 2015 with relevant departments of WHO, relevant organizations of the United Nations (the Secretariat, UNMEER, the Office for the Coordination of Humanitarian Affairs (OCHA), the United Nations Development Programme (UNDP), the United Nations Children's Fund (UNICEF) and the United Nations Population Fund (UNFPA), the World Bank, research institutes (NAM), think tanks (the Council on Foreign Relations, the Center for Strategic and International Studies), the Bill and Melinda Gates Foundation, and others.

2 Formerly, the Institute of Medicine (IOM). 


\section{Response to the Ebola virus disease outbreak}

Regarding the spread of the Ebola virus disease, MSF and other organizations issued several warnings at the initial stage. WHO could not have been unaware of these warnings (Farrar and Piot, 2014). Much criticism has been levelled at the delay in declaring PHEIC, ${ }^{3}$ the lack of leadership (WHO Ebola Interim Assessment Panel, 2015), and other shortcomings in the WHO responses.

Issues were identified at different levels of WHO (level of relationships among departments within the headquarters, and level of relationships between the headquarters and the regional offices). In addition, there are also issues concerning the affected countries, as well as insufficient utilization of the existing United Nations frameworks for coordination that were already embedded at the international and national levels.

The subsequent analysis is from two perspectives: (a) a spatial perspective (local and national levels, as well as regional and global levels): and (b) a temporal perspective (the stage until a decision is made on a response, and the implementation stage after the decision is made). For each spatial level, both the stage up to when a decision was rendered and the implementation stage will be discussed.

\section{Responses and issues at the local and national levels}

Important factors related to the delays in country responses to the Ebola virus disease outbreak include insufficient collection of information in the field, and prioritization of political, economic, and social considerations over the need to respond to the health crisis based on the available information. Governments worried about negative repercussions, such as travel restrictions and the impact on trade if they were to report on the actual state of the infection and then WHO declared PHEIC. Accumulating accurate information is essential for deciding on measures to counter an infectious disease, but as MSF found in its review, the Governments of Guinea and Sierra Leone, in particular, were very reluctant to cooperate initially (MSF,

\footnotetext{
3 The WHO Ebola Interim Assessment Panel (2015, p.15, box) pointed out the following as the reasons for the WHO PHEIC delay: (a) country factors (weak health systems, insufficient community mobilization, unsafe practices in burials, among others); (b) country politics (concern about political and economic impact); (c) WHO politics/dilemmas (concerns about challenging governments, understandable worries about economic and trade implications, hesitation since the H1N1 response, lack of data, among others); (d) the WHO organizational culture (it has a technical, normative culture, not accustomed to dealing with such large-scale, long-term and multi-country emergency responses occurring in Member States); and (e) international community (it failed to heed warnings because previous Ebola outbreaks were small and contained; there was no intermediate level of warning between the outbreak and the declaration of PHEIC).
} 
2015, p. 8). It has also been reported that, despite the infection having crossed the border and shifted to Sierra Leone in March, the Government of Guinea did not communicate such information (Garrett, 2015).

Although there were a number of intentional factors, a fundamental factor was the fragile health systems of the affected countries stemming from not having thoroughly built IHR core capacities. Local governments and communities lacked surveillance capabilities and laboratory services. They were also deficient in terms of personnel, knowledge and experience, and it was difficult for them to ascertain the true state of the situation.

At the stage when the response was implemented, many of the already insufficient numbers of health workers had fallen victim to the infection, which made the response even more difficult. Moreover, the lack of laboratories within those countries held up prompt determination of the infectious disease and hindered efforts to trace people who had come into contact with the infection. It has also been pointed out that because the initial contact tracing for Guinea was insufficient, it allowed further spread of the infection (Briand and others, 2014). Furthermore, what made the response even more difficult during the implementation stage was lack of active cooperation at the local level, a scope that encompasses local governments and communities. The continuation of internal armed conflicts had developed a strong distrust of the Government, which hindered the engagement of local communities that the international organizations had attempted to promote.

The United Nations Country Teams (UNCTs) could have strengthened the response at the national level. In fact, the United Nations was working within one framework. Within the United Nations Development Assistance Framework (UNDAF), under the overall leadership of the resident coordinator, it would have been possible to coordinate the health sector to strengthen a response with $\mathrm{WHO}$ at the core. Coordination was also considered using the health cluster led by WHO under the leadership of the humanitarian coordinator dispatched by OCHA. ${ }^{4}$ Nevertheless, a sufficient response was unable to be met out through these frameworks.

The main factors were the small WHO presence in such frameworks, insufficient leadership by resident coordinators, absence of any switch from resident coordinators to humanitarian coordinators, and failure to develop responses employing liaisons among existing organizations in each country.

\footnotetext{
4 At the global level, coordination among international organizations and other humanitarian actors is carried out by the Inter-Agency Standing Committee (IASC) chaired by the United Nations Emergency Relief Coordinator, while OCHA serves as the secretariat. For each affected country, OCHA may appoint a humanitarian coordinator, activating the cluster approach, including the health cluster.
} 
The factors that led to the delay in the WHO global emergency response are problems with the Regional Office for Africa (AFRO), insufficient coordination between AFRO and the WHO headquarters in Geneva, and factors within the WHO headquarters.

\section{Regional Office for Africa capacity and insufficient coordination between AFRO and WHO-Geneva}

When considering that the Western Pacific Regional Office (WPRO) played a significant role during the SARS epidemic, which ended in 2003 , the role played by AFRO in failing to contain the infectious disease in the region cannot be ignored. Among the factors cited as contributing to the malfunction of AFRO are a shortage of human resources and budgetary limitations. There were not even 10 staff members working in the department of AFRO handling emergency responses at that time, and the Office had also been limited by budget cuts in recent years. It has been pointed out that functions of AFRO pertaining to surveillance and support of countries where outbreaks of infectious diseases occurred did not function adequately (WHO Ebola Interim Assessment Panel, 2015, para. 45).

In addition, the insufficient working relationship among the affected countries, AFRO, and WHO headquarters was presumed to be one of the factors that delayed the response. Regional offices are highly independent and operate based on rules under an organizational structure that is unique to their respective regions.

On 24 July 2014, the Sub-regional Ebola Operation Coordination Centre (SEOCC) was established with AFRO at the core to serve as a platform supporting the affected countries in West Africa. This was an innovative framework, which had as participants not only WHO, but also OCHA, UNICEF, the World Food Programme (WFP), the Centers for Disease Control (CDC) of the United States, and other organizations. However, in mid-August, a new initiative at the United Nations Headquarters was launched, and then the central role of SEOCC went by the wayside. SEOCC was consequently closed down with the establishment of UNMEER.

\section{World Health Organization headquarters in Geneva}

The following factors caused a delay in launching the initial response and in declaring PHEIC.

First, accurate information was not communicated because of insufficient implementation of IHR monitoring on account of a lack of human and budgetary resources. It has been pointed out that at the end of April when figures of infection temporarily trended downward, foreign aid was withdrawn based on a mistaken 
understanding by CDC that the situation was under control (Garrett, 2015). Such a mistake might have been prevented if there had been more robust surveillance systems at the local and national levels.

Second is the gap between the roles perceived by the WHO Director-General and those demanded of WHO by the international community, along with the lack of leadership exercised during the health emergency. As symbolized by the criticism (Gostin, 2014) of the WHO Director-General's statements that "WHO is a technical agency" and "governments have the primary responsibility" (Fink, 2014), there was a discrepancy between the role that the international community expected of WHO and the organization's own perception of its role. Clearly, even though it is correct that the countries should have the primary responsibility, there was room for WHO to exercise leadership based on information provided by third parties such as MSF. At the Global Outbreak Alert and Response Network (GOARN) meeting held in July, MSF pleaded for an immediate global emergency response, but it was not taken seriously (MSF, 2015, p. 8). This delayed the timing for convening an IHR committee meeting to declare PHEIC.

Third, there was a negative perception of declaring PHEIC within WHO. Specifically, it was (a) considered a last resort (Garrett, 2015) because there was concern that it would impose de facto restrictions on the target country, (b) there were concerns that intervention would be seen as interference in the domestic affairs of a sovereign State, and (c) there was hesitation on account of criticism that had been levelled in the past about the H1N1 response, which was the first PHEIC case, but was considered as an overreaction by WHO. Such factors are thought to have delayed the PHEIC declaration.

One issue in terms of internal coordination within WHO headquarters at the implementation stage is the coordination exercised among different departments. As WHO has also acknowledged, the systems that handled health security and humanitarian issues operated separately (WHO, 2015b, para. 17). Coordination involving the department for health security responsible for IHR and GOARN, the department for humanitarian and emergency responses responsible for polio and emergency medical teams (EMTs), ${ }^{5}$ and the department responsible for long-term strengthening of health systems did not function well initially.

Specifically, there are two broad frameworks for physicians active in the field: (a) GOARN and (b) EMTs. Within WHO, the departments handling these teams were different. The main purpose of GOARN is to respond to infectious diseases; WHO

5 Formerly called the Foreign Medical Teams (FMTs). 
serves as its secretariat. It is a network of partner organizations. Those dispatched are technical personnel. They were effective in responding to SARS and other outbreaks in the past (Mackenzie and others, 2014). GOARN has been set up in the Department of Global Capacities Alert and Response (GCR). On the other hand, EMTs were established in the Emergency Risk Management and Humanitarian Response Department that mainly deals with trauma-related disasters caused by natural or human-induced factors. The reason why collaboration was difficult between those departments within WHO needs to be further explored, however, it is conceivable that the heads of the respective departments did not communicate well, or that there were delays in issuing decisions and instructions by supervisors in both departments.

\section{Coordination within the United Nations family}

There was initially a search for the possibility of using existing frameworks to coordinate in the field when a response began to be considered by the Secretariat.

If a response had been initiated earlier, it might have been possible for humanitarian coordinators supported by OCHA to be dispatched. However, because intervention was called for after the situation had acutely worsened, and because the humanitarian community was not familiar with the Ebola virus, it was determined that a response would be difficult using the cluster approach with OCHA at the core. In addition, rapid access to a large amount of funding was imperative at that time, but that would have been difficult using the usual funding process of OCHA, the Humanitarian Programme Cycle consisting of five elements (needs assessment and analysis, strategic response planning, resource mobilization, implementation and monitoring, and operational review and evaluation). It was assumed that more time would be required to reach a consensus on using the Central Emergency Response Fund (CERF) for the Ebola virus disease response, which is different than what is used for ordinary natural disasters and armed conflicts.

In the ultimate response to this situation in September 2015, it was common agreed that the establishment of UNMEER could be justified based on the SecretaryGeneral's initiative to mobilize resources, procure funding, and coordinate United Nations organizations in a top-down manner over a short period of time. ${ }^{6}$

\footnotetext{
6 WHO Ebola Interim Assessment Panel (2015) stated it was clear that leadership at the SecretaryGeneral level was needed in September 2014. However, it went on to state that when large-scale health crises were to arise in the future, the UNMEER model would not be appropriate, and it strongly opposed the establishment of a United Nations mission. It pointed out that an emergency coordinator might be set up at the regional level for operations and that the Sub-regional Ebola Operation Coordination Centre (SEOCC) could have coordinated the Ebola response (WHO Ebola Interim Assessment Panel, 2015, para. 77-81).
} 
Nevertheless, this is not to say that there were no issues to be addressed in the UNMEER response. More specifically:

(a) The construction of a new organization gave rise to problems, such as coherence and overlapping issues with the aforementioned existing frameworks (overlapping with $\mathrm{OCHA}$ and the United Nations Development Group coordination frameworks present at the international level, as well as with the Ebola response frameworks established by national governments).

(b) Initially, because the operation was conducted in a top-down manner and emphasized military-like logistics, there was also confusion in the field. For example, comments were voiced that cultural factors, such as traditional practices for the deceased, should also have been emphasized.

(c) Although UNMEER made it possible to take swift action with a clear division of labour, it took some time for the process to begin to operate substantively. It was in October when the Accra meeting was held, in which the division of work among international organizations was completed and substantive deployments initiated.

(d) The above analysis shows that the factors resulting in the delayed response to the Ebola virus disease, leading to a more serious situation, were issues pertaining to coordination and issues involving gaps in information and perception among a variety of actors at various levels.

\section{RESPONSE OPTIONS FOR GLOBAL HEALTH GOVERNANCE}

Taking into account the above analysis of the process of responding to the Ebola outbreak, the following response options along two broad topics are proposed. One is to build capacities to respond during an emergency situation, and the other is to strengthen health systems during ordinary times. The success of emergency responses depends on the health systems, which ensures that information is collected and responses are implemented during ordinary times. The systematic infrastructure for collecting information for an emergency response, as well as for implementing responses can also be used during ordinary times. In addition, increasing the efficiency of emergency responses spares resources and allows for expanded access to be secured within the health systems during ordinary times. In that sense, these two topics are closely related. 
Below, response options related to those two topics from two perspectives are presented: (a) building organizational capacities; and (b) enhancing coordination among organizations.

\section{RESPONSE CAPACITIES DURING A HEALTH EMERGENCY}

\section{Organizational capacity for an incremental response}

One factor leading to a delay in the response was that there was no intermediate stage between ordinary times and PHEIC. PHEIC determination is a clear choice between two alternatives, and there is no framework allowing for progressive stages of response. In order to execute progressive stages of response, (a) the construction of a framework for making progressive determinations about the situation, and (b) building capacities to gather information to support such judgments are required.

With regard to (a), multiple stages need to be established to allow a progressive response between the non-PHEIC situations and the current PHEIC. ${ }^{7}$ In IHR, the Article 8 states that consultations with WHO on appropriate measures may be conducted through the national IHR focal point even for information not required to be reported, particularly for events for which there is insufficient information available to complete a decision on whether it constitutes PHEIC. Such a provision should be used to build an operational framework for collecting a broad range of information and making stage-based situational determinations. It is also important to strengthen the risk assessment capability of WHO and staffing to allow for the operation of such a framework. However, care needs to be taken so that the criteria for judgments can operate with some flexibility.

With regard to (b), the current IHR (2005) allows for the use and analysis of information sourced not only from countries, but also from other sources (Article 9.1), including international organizations, non-State actors, and a variety of other entities. This was the strategy applied to overcome two potential limitations of surveillance under the previous IHR (1969): inadequate capacities at the local and national levels to fulfil surveillance, and government reluctance to comply for fear of the adverse consequences of reporting. However, such WHO authority and capabilities are not sufficiently used. Pursuant to this provision, WHO should consider the development of

The need for emergency grading levels is also recommended in the WHO Panel report. The PHEIC determination is a single binary decision, and the Panel recommends that the IHR Review Committee for Ebola consider the possibility of alerts at an intermediate level to mobilize the international community (WHO Ebola Interim Assessment Panel, 2015, para. 23). 
a mechanism for collecting a broader range of information to adopt necessary measures, including in cases where there may not be a clear indication of PHEIC and also from a variety of sources that are active at the grassroots level, such as MSF.

In all of the above-mentioned judgment stages, it is also fundamental to acknowledge that the governments and leaders of the countries concerned have the primary responsibility and should play a leading role.

\section{Organizational capacity to respond to diverse situations}

In this response to the Ebola virus disease outbreak, operations were deployed on a large scale in both the humanitarian community and the health security community. However, unlike in the case of the Polio response in which both communities collaborated on a daily basis, there were no routine procedures and protocols for the Ebola response. Cultural and organizational differences between the two surfaced, rendering cooperation difficult. A new arrangement that allows for stagebased and flexible collaboration in responding to a variety of situations, as has been discussed above, is needed.

The need for an integrated programme for emergencies was recognized, and a decision was made to establish such a programme at the sixty-eighth World Health Assembly of WHO, which was held in 2015. The proposal of an Advisory Group on Reform of WHO's Work in Outbreaks and Emergencies is in line with this direction (WHO Advisory Group, 2015). ${ }^{8}$ In many review reports, differences between these two communities have been highlighted and calls have been made to strengthen coordination and merge the humanitarian community and the health security community. The WHO secretariat has reviewed a variety of framework liaisons, such as GOARN and EMTs, which have previously been handled by separate departments, to be merged into one cluster. Through the recent organizational restructuring, these two departments have been merged into one cluster. Similarly, it may be worth noting that at the regional office level, in the case of WPRO, both humanitarian and health security departments are dealt with under the Division of Health Security and Emergencies.

\footnotetext{
8 Although established within $\mathrm{WHO}$, it is an independent organization. It provides centralized management of units and functions at all levels, national, regional and the WHO headquarters. Discussions have been held about the necessity for having this programme cite PHEIC cases and IHR contact points (WHO Advisory Group, 2015, para. 6).
} 


\section{Situational categories for health emergencies and the coordination patterns}

Every emergency occurs under different conditions, and coordination and cooperation are required based on each circumstance. As a result, the mechanism necessarily differs depending on the type of the situation. A "switch function," which enables the change of the leadership, is critical in applying situation and stage-based framework.

There is a clear need to develop situation-based flexible partnerships for coordination and cooperation among international organizations (relationships between $\mathrm{WHO}$ and the humanitarian community, the development community and the security community). WHO is definitely the only actor that can perform the central leading role in providing technical and medical recommendations concerning a health crisis. However, as was evident in the lessons learned from the Ebola outbreak, health crises often entail situations that cannot be dealt with by just furnishing technical knowledge, guidelines, and a limited deployment of technical and medical experts. Consequently, diverse international emergency situations need to be anticipated, and diverse patterns for coordination and cooperation among international institutions for each situation need to be prepared.

The patterns of coordination and cooperation differ depending on the capacity of the affected country and the type of infectious diseases. Therefore, as to the question of who should develop what sort of initiative at the international level, the following options can be considered depending on situational categories that are based on (a) the capacity of the country where an infectious disease outbreak has occurred requiring the response, and (b) the severity and the magnitude of the infectious disease.

Type 1 cases, in which the country where the outbreak has occurred maintains a high response capacity and the degree of severity of the infectious disease and the magnitude of its impact are low, responses may be handled by the country concerned with minimal support from WHO. In Type 2 cases, the country and WHO are central in handling the situation, and support from organizations other than WHO may also be necessary.

In Type 3 cases, under the existing UNDAF framework, the resident coordinator provides overall coordination, within which WHO leads the health sector, and a response is extended while obtaining the cooperation of a variety of international organizations of the United Nations Country Team. In Type 4 cases, there is a greater sense of urgency and more humanitarian elements are required than afforded by the development framework for ordinary times. In these cases, a framework is implemented in which OCHA deals with the humanitarian crisis, and 


\section{Table 1. Situations categories for health emergencies and the coordination patterns}

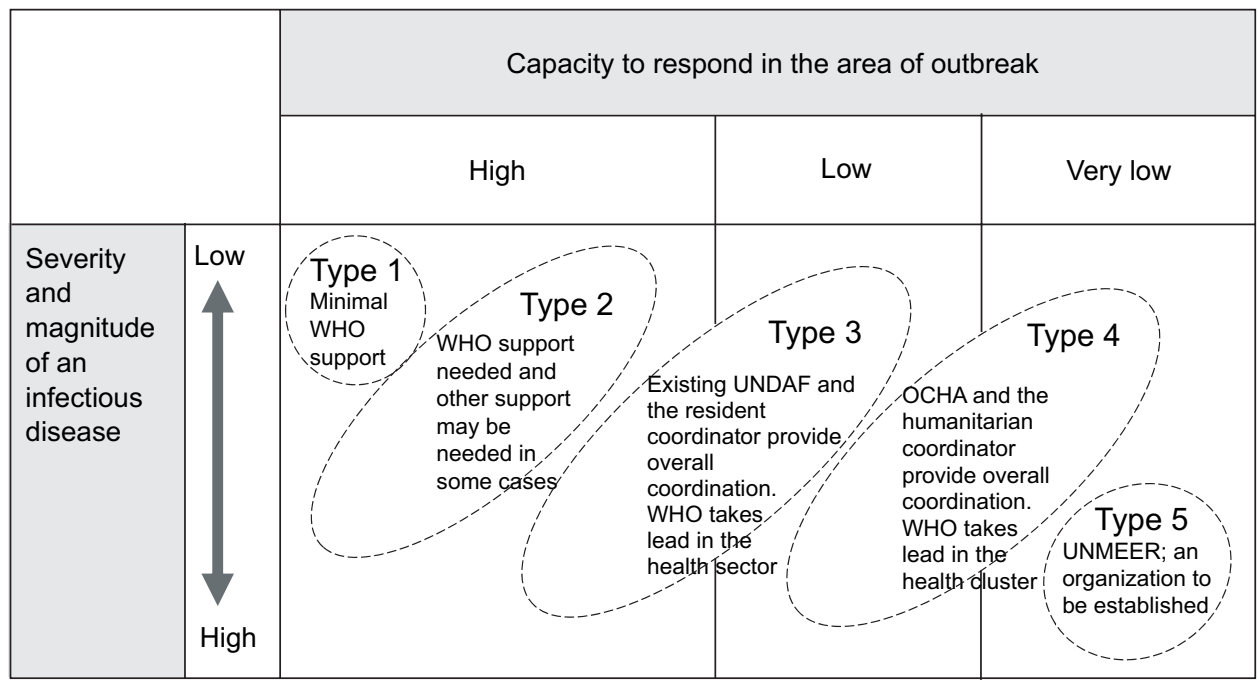

Source: Compiled by the authors.

the humanitarian coordinators exercise overall coordination in affected countries under the leadership of the United Nations Emergency Relief Coordinator at the global level, in which WHO plays a central role in leading the health cluster.

Lastly, Type 5 cases are those in which it is determined that a response is beyond OCHA or existing frameworks' capabilities, and are handled by establishing a new organization through the strong political initiative of the Secretary-General to serve as a measure to counter the infectious disease, such as UNMEER in the case of the Ebola virus disease. Moreover, in cases in which serious crises are dealt with, it is also conceivable that a United Nations peacekeeping operation, military, or other security maintenance organizations in the security community may also be used. In the present case, a resolution was passed by the Security Council to endorse the establishment of UNMEER, which has the advantage of being effective in heightening awareness of the international community because of its binding power and high political importance. If the United Nations Department of Field Support in charge of the peacekeeping operation takes a logistical approach, then a quick and efficient response may be implemented. However, there are also elements that place the operation in a tense relationship from the perspective of democracy. Outbreaks classified as Type 5 are extraordinary cases, and the establishment of a new 
permanent organization is not desirable. It is important that cases be dealt with using organizations for limited periods with clear mandates.

\section{Coordination and the person responsible for the "switch function"}

The following two points must be emphasized. First, an issue in terms of operation in the cases of outbreak Types 3,4 and 5 is that coordination and cooperation between the health security community and the humanitarian community are important because the objectives, themes, and organizational culture differ for each community. The issue of coordination between the humanitarian and health security communities is present not just within $\mathrm{WHO}$, but also in relationships between WHO and other organizations within the United Nations system, working together in the health sector or cluster.

Second, because circumstances may change, the necessary patterns of coordination and cooperation need to be continuously reassessed based on changing situational categories. For example, there is continuity in changes of circumstance that necessitate a switch from Type 3 to Type 4. Accordingly, it is important that there be a "switch" that alters the patterns of coordination and cooperation discontinuously by taking into account ongoing circumstances. Particularly in cases in which a coordinating body is already present under an existing framework, such as a United Nations Country Team resident coordinator, it is necessary to allow for an honourable replacement with a humanitarian coordinator from $\mathrm{OCHA}$, or a new organization, such as UNMEER. For this reason, it may also be necessary to prepare in advance a protocol that enables smooth switches. Ultimately, the person responsible for the "switch function" should be the Secretary-General or the Chef de Cabinet.

\section{STRENGTHENING HEALTH SYSTEMS DURING ORDINARY TIMES}

It is important that the strengthening of health systems during ordinary times be supported so that an early warning may be signaled to prevent outbreaks before they happen. The collection of information and systematic infrastructure for responding during emergencies to specific infectious diseases can also be used by the health systems during ordinary times as well in a cross-sectional manner to address diseases. Therefore, the governance structure and design of response measures during times of emergencies should be closely linked to reinforcing the health systems during ordinary times. 


\section{Building International Health Regulations core capacities at the country level}

To effectively respond to infectious diseases, it is necessary that the IHR core capacities be built up in countries when strengthening the health systems. Currently, in AFRO, not one country has completed implementation of building the minimum core capacities for IHR (WHO AFRO, 2015). Of the eight IHR core capacities, ${ }^{9}$ it is particularly essential that surveillance, human resources, and laboratory services be built so that stage-based decisions may be made about situations based on best available information. Along with a framework seamlessly linking a variety of levels (community $\Rightarrow$ local government $\Rightarrow$ country $\Rightarrow$ regional $\Rightarrow$ global), partnerships also need to be created with the private sector to develop surveillance, laboratory services, and human resources. It is necessary that the range of information to be reported be expanded.

\section{International monitoring of the implementation of International Health Regulation in individual countries}

To strengthen the implementation of IHR at the country level, monitoring at the regional level must be enhanced. First, WHO regional offices must be beefed up. To build up staffing, as WPRO has done, it is important that "truly international" staff be employed based on their ability to ensure diversity and capabilities. To achieve this, reforms may be necessary. One example may be to impose an obligation on all regional offices to recruit on the basis of ability a certain percentage of the staff from outside the region. However, this does not mean that the independence per se of regional offices is bad (during the SARS response, the discretion of WPRO enabled early containment). Verification of the effectiveness of strategic frameworks, for example, the Asia Pacific Strategy for Emerging Diseases (APSED) of WPRO and the Integrated Diseases Surveillance and Response (IDSR) of AFRO in the implementation of IHR also appears to be needed.

Second, regional monitoring must be strengthened. For example, the establishment of a version of CDC for the Africa Union has been proposed. These activities need to be linked with actors other than those in the public sector.

At the global level, departments within WHO concerned with health emergency need to be strengthened. Current debate is focused on coordination between departments involved with emergencies and humanitarian issues, and those concerned with health security, but if continuity between times of emergency and

The eight IHR core capacities are (1) national legislation, policy and financing, (2) coordination and national IHR focal points communication, (3) surveillance, (4) response, (5) preparedness, (6) risk communication, (7) human resources and (8) laboratory services. 
ordinary times is taken into consideration, then it is also important to rank the strengthening of IHR core capacities as one element in strengthening health systems to ensure coordination between the health security department and the health system department.

\section{Coordination among diverse organizations supporting the enhancement of International Health Regulations}

A cooperative framework must be developed to enable organizations and frameworks outside the health sector to directly and indirectly support the enhancement of IHR.

As a condition for building a cooperative framework, it is necessary to recognize that IHR is based on an "all hazard" approach. The commitment of organizations in a variety of fields, such as development, trade, disaster prevention and security, are needed for an all hazard responses. To ensure such a commitment from a diverse range of organizations, this commitment must be endorsed not only at the level of the health minister but also from the top national level.

As its presence at the country level is not necessarily sufficient, it is difficult for WHO to play a direct role in the enhancement and monitoring of the implementation of IHR in all countries. International organizations active in the field, such as UNDP and UNICEF, need to acknowledge that enhanced IHR core capacities contribute to the overall strengthening of the health systems in developing countries, and play a role in monitoring whether the IHR requirements of core capacities are met in each country.

In addition, there is the issue of what to do about measures involving unnecessary trade restrictions that may potentially be adopted by neighbouring countries when a certain country reports information that may constitute PHEIC. With regard to this, a framework may be strengthened to check the appropriateness of measures under IHR, and coordination may be pursued with actors in other sectors, such as WTO. ${ }^{10}$ The Sanitary and Phytosanitary (SPS) Agreement of WTO states that when national standards that are stricter than international standards are adopted, the national standards must be scientifically justified. For example, in the case in which Europe instituted trade restrictions during a cholera outbreak in Africa, the SPS Committee of WTO deliberated on the restrictions, including a scientific debate on the risk these measures pose to public health, which resulted in the trade restrictions being lifted (WHO and WTO, 2002).

\footnotetext{
10 There have been discussions that this sort of approach may be useful in preventing surrounding countries from adopting overly restrictive measures on the movement of people and goods during the implantation of IHR.
} 
It is also important that bilateral and multilateral development organizations coordinate with each other from the perspective of security. Collaboration with initiatives, such as the Global Health Security Agenda (GHSA), is already under way, including the joint external evaluation tool for IHR formulated by WHO with GHSA, a multilateral framework led by the United States, which has stated that it will achieve its goals in at least 30 countries over the next five years, and has declared that it will invest US $\$ 1$ billion in 17 countries towards this effort. The United States has called for donor countries to participate in GHSA, and at the G7 Summit in 2015, it was agreed that development assistance would be provided to 60 countries overall, including countries in West Africa. Although the countries targeted are limited, this initiative can contribute to a rapid build-up of IHR core capacities. The merit of this kind of initiative is that it has a strong political commitment from the perspective of security and is useful for tackling issues that cannot be dealt with under existing frameworks. However, on the other hand, the negative include dependence on political momentum, and the challenge of institutionalization to extend such efforts sustainably.

\section{FUTURE CHALLENGES}

This paper presents issues to be addressed and lessons learned based on an analysis of the process of the response to the Ebola virus disease outbreak, and proposes options for addressing global health governance. These issues of global health governance are important for the means of implementation in the efforts to achieve the Sustainable Development Goal aimed at ensuring healthy lives and promoting well-being for all at all ages.

Currently, international interests and assessments appear to be focused on improving organizational coordination between health security and humanitarian aid, which is necessary for responding to infectious diseases, such as Ebola, and on the necessity for the general strengthening of health systems. However, focus on improvement of organizational coordination has been narrowed down to mainly improvements within WHO. Consideration needs to be given to issues related to organizational coordination across the entire United Nations system, including OCHA and United Nations Development Group members.

Additionally, it is important that responses to such specific infectious diseases are positioned within the cross-sectional and comprehensive reinforcement of health systems, which makes such monitoring possible, and are linked to strengthening health systems in countries, as well as to universal health coverage, target 3.8 of the Sustainable Development Goal 3. Generally speaking, an emergency response depends on the health systems employed during ordinary times, which provides the systematic infrastructure for information collection and response. On the other hand, 
the systematic infrastructure for information collection and response that is developed for use in emergency response to health risks (target 3.d) can also be used during ordinary times. Furthermore, improving the efficiency of emergency responses allows for resources to be secured in order to expand access to health systems during ordinary times. However, the paths for undertaking such linkages differ depending on the country.

Although it has been discussed in the debate over PHEIC, a point that has not been sufficiently delved into is the issue of constructing mechanisms for collecting information about events that occur at levels below PHEIC and how to control the unnecessary restrictions on trade or in other areas. With regard to these, further research is necessary as to whether IHR needs to be revised, whether it needs to be adapted in terms of operation, or whether considerations are needed with other systems, such as funding mechanisms or WTO.

In addition, the importance of the Secretary-General and the Chef de Cabinet at the United Nations Headquarters as the key persons responsible for the "switch function" from ordinary times to emergency situations involving a change in leadership roles has been delineated, but the remaining issue is how to institutionalize such mechanisms at the global level.

Furthermore, responses must also be considered in line with specific scenarios in cases in which an outbreak occurs not in a vulnerable country, such as where the Ebola outbreak spread, but for instance, in large countries in Asia, such as China and India, where pandemics develop due to a different infectious diseases, such as airborne influenza. The table above needs to be used to review a variety of stagebased response modes in keeping with the terms of global health governance by conducting reviews on the capacity to respond to specific infectious diseases at multiple levels (national, regional and global) in accordance with the situational categories based on the combination of the country (high or low) where the outbreak has occurred and the type of infectious disease. 


\section{REFERENCES}

Briand, Sylvia, and others (2014). The Ebola emergency. New England Journal of Medicine, vol. 371, No. 13 , pp. 1180-1183.

Farrar, Jeremy J., and Peter Piot (2014). The Ebola emergency? Immediate action, ongoing strategy. New England Journal of Medicine, vol. 371, No. 16, pp. 1545-1546.

Fink, Sheri (2014). W.H.O. leader describes the agency's Ebola operations, New York Times, 4 September.

Garrett, Laurie (2015). Ebola's lessons: how the WHO mishandled the crisis. Foreign Affairs, September/October Issue.

Gostin, Lawrence O. (2014). Ebola: towards an international health systems fund. The Lancet, vol. 384, No. 9951, pp. 49-51.

Gostin, Lawrence, and Eric A. Friedman (2014). Ebola: a crisis in global health leadership. The Lancet, vol. 384, No. 9951, pp. 1323-1325.

Kruk, Margaret E., and others (2015). What is a resilient health system? Lessons from Ebola. The Lancet, vol. 385, No. 9980, pp. 1910-1912.

Mackenzie, John S., and others (2014). The Global Outbreak Alert and Response Network. Global Public Health, vol. 9, No. 9, pp. 1023-1039.

Médecins Sans Frontières (MSF) (2015). Pushed to the limit and beyond a year into the largest ever Ebola outbreak. Available from www.doctorswithoutborders.org/sites/usa/files/ msf143061.pdf.

Moon, S. and others (2015). Will Ebola change the game? Ten essential reforms before the next pandemic. The report of the Harvard-LSHTM Independent Panel on the Global Response to Ebola. The Lancet, vol. 386, No. 10009, pp. 2204-2221.

WHO Advisory Group (2015). Advisory Group on reform of WHO's work in outbreaks and emergencies. First report, 6 November. Available from www.who.int/about/who_reform/ emergency-capacities/advisory-group/face-to-face-report-executive-summary.pdf?ua=1.

WHO Ebola Interim Assessment Panel (2015). Report of the Ebola Interim Assessment Panel. Available from www.who.int/csr/resources/publications/ebola/ebola-panel-report/en/.

World Health Organization (WHO) (2015a). Follow up to the World Health Assembly decision on the Ebola virus disease outbreak and the Special Session of the Executive Board on Ebola: roadmap for action. Available from http://apps.who.int/about/who_reform/emergencycapacities/WHO-outbreasks-emergencies-Roadmap.pdf?ua=1.

(2015b). WHO secretariat response to the report of the Ebola Interim Assessment Panel, 19 August. Available from www.who.int/csr/resources/publications/ebola/who-response-toebola-report.pdf?ua=1.

(2016). Ebola situation report, 30 March. Available from http://apps.who.int/ebola/currentsituation/ebola-situation-report-30-march-2016.

World Health Organization, Regional Office for Africa (WHO AFRO) (2015). Integrated disease surveillance quarterly bulletin, May. Available from www.humanitarianresponse.info/en/ system/files/documents/files/integrated_disease_surveillance_quaterly_bulletin_ 31_may_2015.pdf.

World Health Organization, and World Trade Organization (WHO and WTO) (2002). WTO Agreements and Public Health: A Joint Study by the WHO and the WTO Secretariat. Geneva: WTO and WHO. 